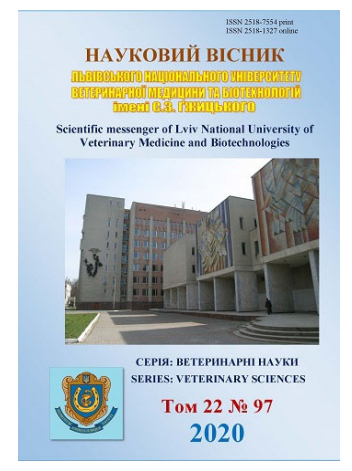

\author{
Науковий вісник Дьвівського національного університету \\ ветеринарної медицини та біотехнологій імені С.3. Гжицького. \\ Серія: Ветеринарні науки
}

Scientific Messenger of Lviv National University of Veterinary Medicine and Biotechnologies. Series: Veterinary sciences

\title{
Validation of a portable ECG monitor for the diagnosis of arrhythmias in horses compared to a standard electrocardiograph
}

\author{
B. Popadiuk, S. Holopura
}

National University of Life and Environmental Sciences of Ukraine, Kyiv, Ukraine

Article info

Received 21.01.2020

Received in revised form 24.02.2020

Accepted 25.02.2020

National University of Life and Environmental Sciences of Ukraine, Potekhina Str., 16 , building 12, Kyiv, 03127,Ukraine. Tel.: +38-098-994-76-13 Tel.: +38-067-789-41-27 E-mail:bogdana.popadiuk@nubip.edu.ua E-mail: golopura@ukr.net

Popadiuk, B., \& Holopura, S. (2020). Validation of a portable ECG monitor for the diagnosis of arrhythmias in horses compared to a standard electrocardiograph. Scientific Messenger of Lviv National University of Veterinary Medicine and Biotechnologies. Series: Veterinary sciences, 22(97), 20-25. doi: 10.32718/nvlvet9704

Electrocardiography (ECG) is a main diagnostic tool for diagnostics of rhythm disturbances. Since most pathological arrhythmias are only visible during movement and exercises the registration of exercising ECG becomes a mandatory diagnostic tool for monitoring of high-performance horses. Portable ECG monitor, developed together with specialists of National Technical University of Ukraine "Igor Sikorsky Kyiv Polytechnic Institute" is an electrocardiograph with telemetric data transmission system and four electrodes providing six-lead real-time ECG recordings at rest and during exercise. The objective of current study was validation of portable ECG monitor for diagnostics of arrhythmias in horses compared to a standard electrocardiograph. With this aim the ECG was performed by both devices simultaneously on animals with normal rhythm and rhythm disturbances. The ECG traces were therefore analyzed and compared. 14 horses of Ukrainian riding, Friesian, and Arabian breeds were divided in two groups: experimental one with arrhythmias, and control one with normal rhythm. ECG was performed by both devices simultaneously during rest, exercise, and post-exercise period. Electrocardiographic parameters were measured manually using on-screen calipers. Obtained data was analyzed using GraphPad Prism software by linear regression method for continuous parameters (HR, duration of QRS complex, $P R$, and $Q T$ intervals, and amplitude of $P$ and $S$ waves). For nominal parameters (rhythm, excitability, and conduction disorders) the analysis of sensitivity and specificity was performed. A total of 196 ECG records were analysed. Electrocardiographic intervals had high correlation: for HR and PR interval the correlation coefficient amounted to 0.98, for QRS complex and QT interval - to 0.97, for $P$ and $S$ waves - to 0.96. Among detected rhythm disturbances were physiological (second degree AV block first Mobitz type and SA block) and pathological arrhythmias (SVT and SVPCS). The sensitivity and specificity for rhythm, excitability, and conduction disorders of the portable ECG monitor compared to a standard electrocardiograph was $100 \%$. The portable ECG monitor allows to easily perform ECG registration during rest and exercises and to detect arrhythmias and other ECG abnormalities with accuracy, compared to a standard electrocardiograph.

Key words: cardiology, electrocardiography, equine, arrhythmias.

Introduction

Arrhythmias are common in horses due to high vagal tone - most of them are physiological and do not pose a threat to animal health. Pathological arrhythmias occur as a result of primary or secondary myocardial disease, noncardiac systemic diseases, intoxication, hypoxia, metabolic and electrolyte imbalances (Verheyen et al., 2010).
An electrocardiography (ECG) is the most important diagnostic tool in cardiology and a mandatory method for the diagnosis of arrhythmias. Main indications for ECG monitoring are: routine monitoring during general anesthesia and intensive care, monitoring during treatment procedure (e.g. antiarrhythmic drug administration such as quinidine) monitoring a patient at risk for developing arrhythmias (e.g. due to electrolyte imbalance) arrhythmia detected on auscultation, exercise intolerance, clinical signs suggestive of syncope, 
underlying cardiac or systemic disorders that might predispose to arrhythmia (Allen et al., 2015). ECG registration can be performed on the animal in a quiet state, including 24-hour holter monitoring, as well as during movement and exercises. The exercise ECG is the best method for detecting and differentiating pathological and physiological arrhythmias and can better assess the prognosis for the animal (Reed et al., 2018).

Portable ECG monitor, developed together with specialists of National Technical University of Ukraine "Igor Sikorsky Kyiv Polytechnic Institute" is an electrocardiograph with telemetric data transmission system and four electrodes providing six-lead real-time ECG recordings at rest and during exercise.

The purpose of this study was to validate a portable ECG monitor for the diagnostics of arrhythmias in horses compared to a standard electrocardiograph (ECGPro IMESC, Ukraine).

\section{Material and methods}

The basis for the research were the stables of the Kyiv region.

Portable ECG monitor is a telemetric system for recording the electrocardiogram with a bluetooth data transfer system to a program installed on a phone or tablet. The device is equipped with an indicator light, a liion battery, a microSD memory card slot, a shock and waterproof coating, and four electrode cables. It provides registration of six ECG leads during 10-12 hours. Singlechannel ECG recording (second lead) can be tracked in real time on a display of a mobile device in a mobile application. At the end of electrocardiogram registration, records are downloaded from a removable storage to a cloud-based web application, with an advanced ECG analysis of three standard leads (I, II and III) and three augmented leads (aVR, aVL and aVF).

Animals. An electrocardiographic study of 14 horses aged 3.5 to 17 years was conducted, including Ukrainian riding, Friesian, and Arabian breeds. Anamnesis was collected during the preparation phase. The condition of the cardiovascular system of animals was evaluated by conducting a physical examination, which included examination of mucous membranes (conjunctiva of the eyes), filling time of the capillaries, apical heartbeat (precordial area), arterial pulse (maxillary and digital arteries), auscultation of the heart - as well as a specific examination using electrocardiography. The horses were divided into two groups - control group $(n=7)$ without arrhythmias and experimental one $(n=7)$ with arrhythmias (Table 1).

Table 1

Breed and age of animals from control and experimental groups

\begin{tabular}{cccccc}
\hline & Control group & \multicolumn{3}{c}{ Experimental group } \\
\hline Name & Breed & Age, years & Name & Breed & Age, years \\
\hline Emir & Ukrainian riding & 3.5 & Inid & Ukrainian riding & 5.5 \\
Peris & Ukrainian riding & 7 & Dunay & Ukrainian riding & 10 \\
Happyk & Ukrainian riding & 11 & Tavr & Ukrainian riding & 15 \\
Zamet & Ukrainian riding & 17 & Yarych & Friesian & 3.5 \\
Diadora & Friesian & 12 & Yanychar & Friesian & 4.5 \\
Karma & Arabian & 4 & Sirius Black & Friesian & 6 \\
Adamus & Arabian & 8.5 & Clarkia & Arabian & 8 \\
\hline
\end{tabular}

For simultaneous registration of electrocardiograms on the body of the animal the electrodes of both devices were attached side by side. For this purpose, a system of 4 electrodes of each device was arranged according to adapted base-apex system as follows: negative (red) electrode was placed on the right in front of the scapula, positive (green) one - on the left directly behind the area of apical beat caudally from the elbow, positive-negative (yellow) one $-5-10 \mathrm{~cm}$ above green, and the refractive (black) electrode - on the left in the area of the blade (Fig. 1). The ECG unit was fixed to the saddle and electrode cable was connected to the ECG unit. The registration of electrocardiograms was performed in three stages:

- the first stage: registration of an ECG at rest before exercise for 10-15 minutes;
- the second stage: ECG registration during exercise for 30 minutes;

- the third stage: ECG registration during rest immediately after exercise for 15 minutes.

Three leads were recorded: I lead - between red and yellow electrodes, II lead - between red and green electrodes, and III lead - between yellow and green electrodes. For better contact of electrodes with the body of the animal, disposable electrode pads with a gel layer and a sticky base were used. The skin areas were not clipped.

The rhythm and the presence of excitability and conduction disturbances were analyzed on electrocardiogram records; measurements of the intervals duration and the waves amplitude were performed. 


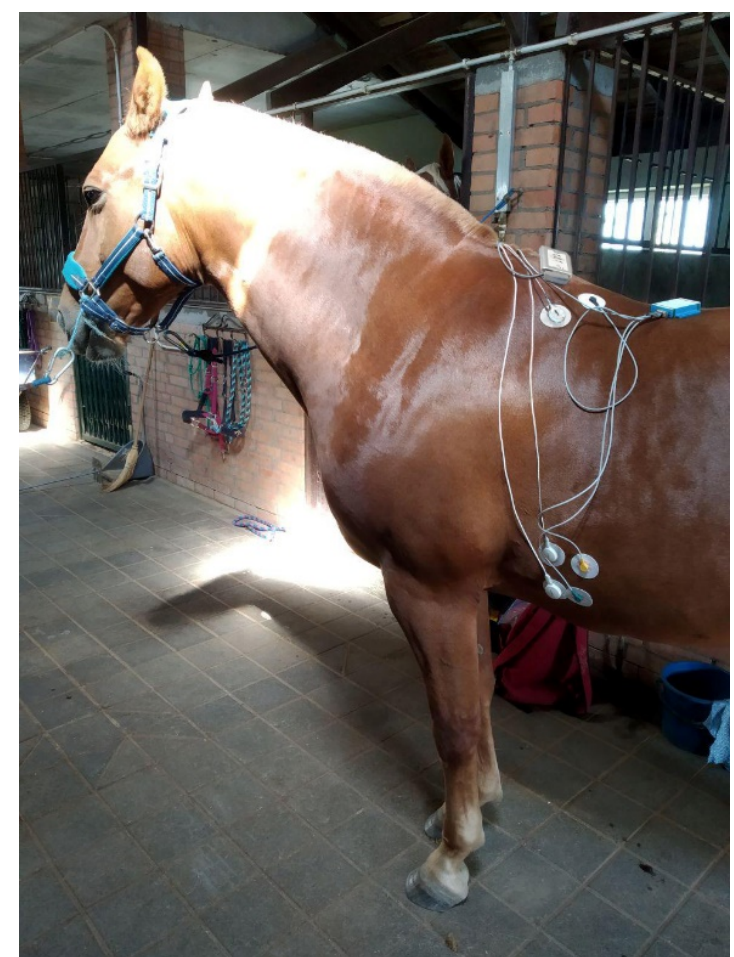

Fig. 1. Photograph of the placement of electrodes from both devices

\section{Results}

The following parameters of electrocardiograms were compared between a portable ECG monitor and a standard electrocardiograph:
- linear regression method for continuous parameters (heart rate (HR), duration of QRS and QT intervals and amplitude of $\mathrm{P}$ and $\mathrm{R}$ waves);

analysis of sensitivity and specificity for nominal parameters (rhythm, excitability and conduction disorders).

A total of 196 ECG records were evaluated for rhythm disturbances. Two records were excluded from study because of poor quality. Main characteristics of the population: $71 \%$ males, mean age 8.3 years $(3.5-17$ years).

Arrhythmias. Eighty-six of the 194 ECG records (44.7\%) revealed rhythm abnormalities, and 26 ECG records $(13.5 \%)$ revealed pathological arrhythmias. One animal was found to have supraventricular tachycardia (SVT) and supraventricular premature contractions (SVPCs) (Fig. 2). Additionally, one animal had SVPCs (Fig. 3) and two animals had sinoatrial (SA) block. Three animals had second degree atrioventricular block (AVB) (Fig. 4).

ECG records of control group showed a sinus rhythm. At the same time, the sensitivity and specificity of the portable ECG monitor compared to a standard electrocardiograph was $100 \%$ (Table 2).

The most common arrhythmia was second degree AV block first Mobitz type. It was detected of accuracy (Table 2). Other arrhythmias - SVPCs, SVT and SA block - were also clearly diagnosed. Difficulties in the diagnosis of SVT and SVPCs are conditioned by the fact that in horses, these rhythm disturbances occur mostly during exercise, while resting ECG may be completely normal.
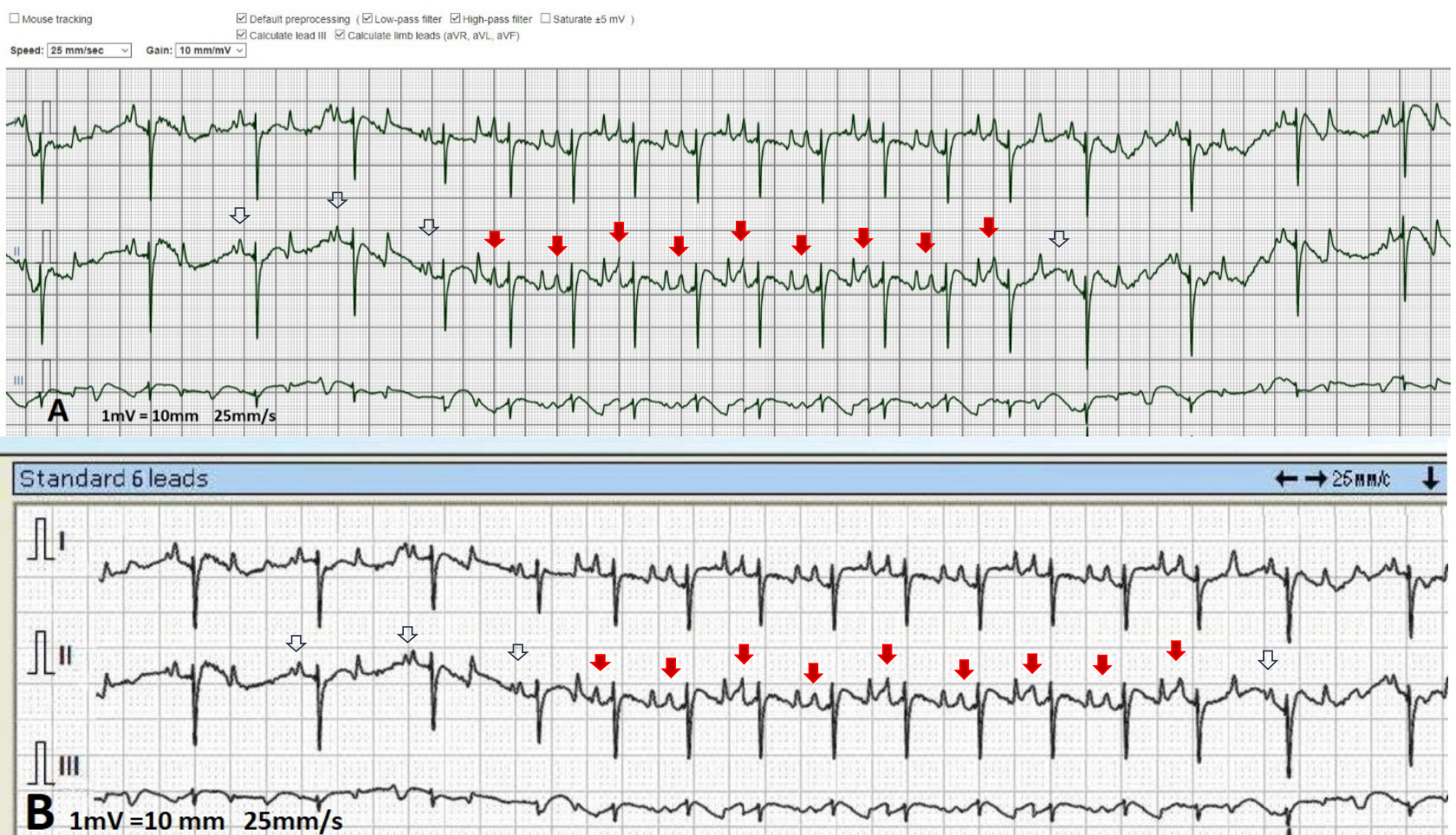

Fig. 2. Example of ECG with SVT recorded simultaneously with a portable ECG monitor (A) and standard electrocardiograph (B). Premature $\mathrm{P}$ waves (filled arrow) have a monophasic morphology, which differs from normal biphasic $\mathrm{P}$ waves (empty arrow), therefore is can be assumed, that premature impulse occurs in the atrial septum (Young, 2004) 
Table 2

Sensitivity and specificity of portable ECG monitor compared to a standard electrocardiograph

\begin{tabular}{lccc}
\hline Rhythm/arrhythmia & Number of animals & Sensitivity & Specificity \\
\hline Sinus rhythm & 7 & $100 \%$ & $100 \%$ \\
SVT & 1 & $100 \%$ & $100 \%$ \\
SVPCs & 2 & $100 \%$ & $100 \%$ \\
SA block & 2 & $100 \%$ & $100 \%$ \\
Second degree AVB & 3 & $100 \%$ & $100 \%$ \\
\hline
\end{tabular}

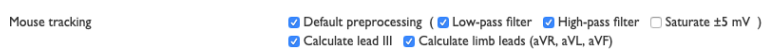 \\ eed: $25 \mathrm{~mm} / \mathrm{sec} \quad$ Gain: $10 \mathrm{~mm} / \mathrm{mV}$ औ}

(1)

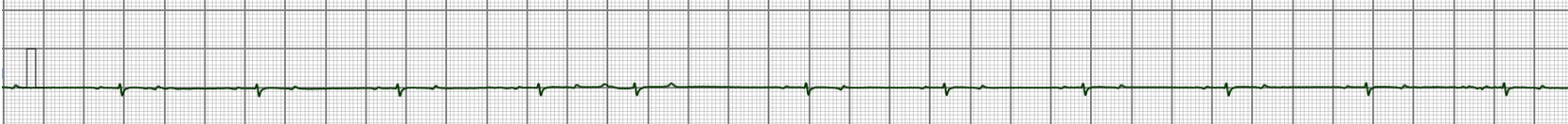

A $1 \mathrm{mV}=10 \mathrm{~mm} 25 \mathrm{~mm} / \mathrm{s}$ | 1 |

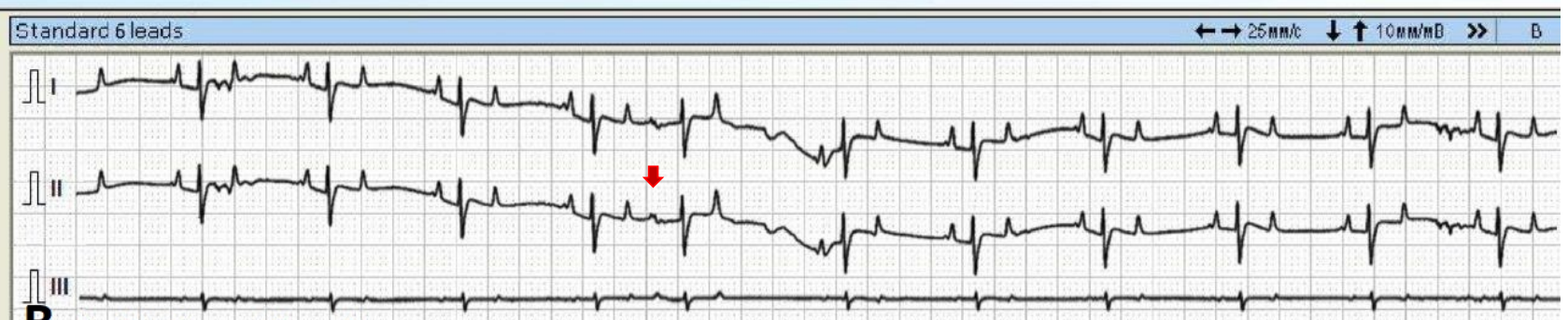

B $1 \mathrm{mV}=10 \mathrm{~mm} 25 \mathrm{~mm} / \mathrm{s}$

Fig. 3. Example of ECG with SVPC recorded simultaneously with a portable ECG monitor (A) and standard electrocardiograph (B). Premature contraction (filled arrow) occurs earlier and is followed by a compensatory pause

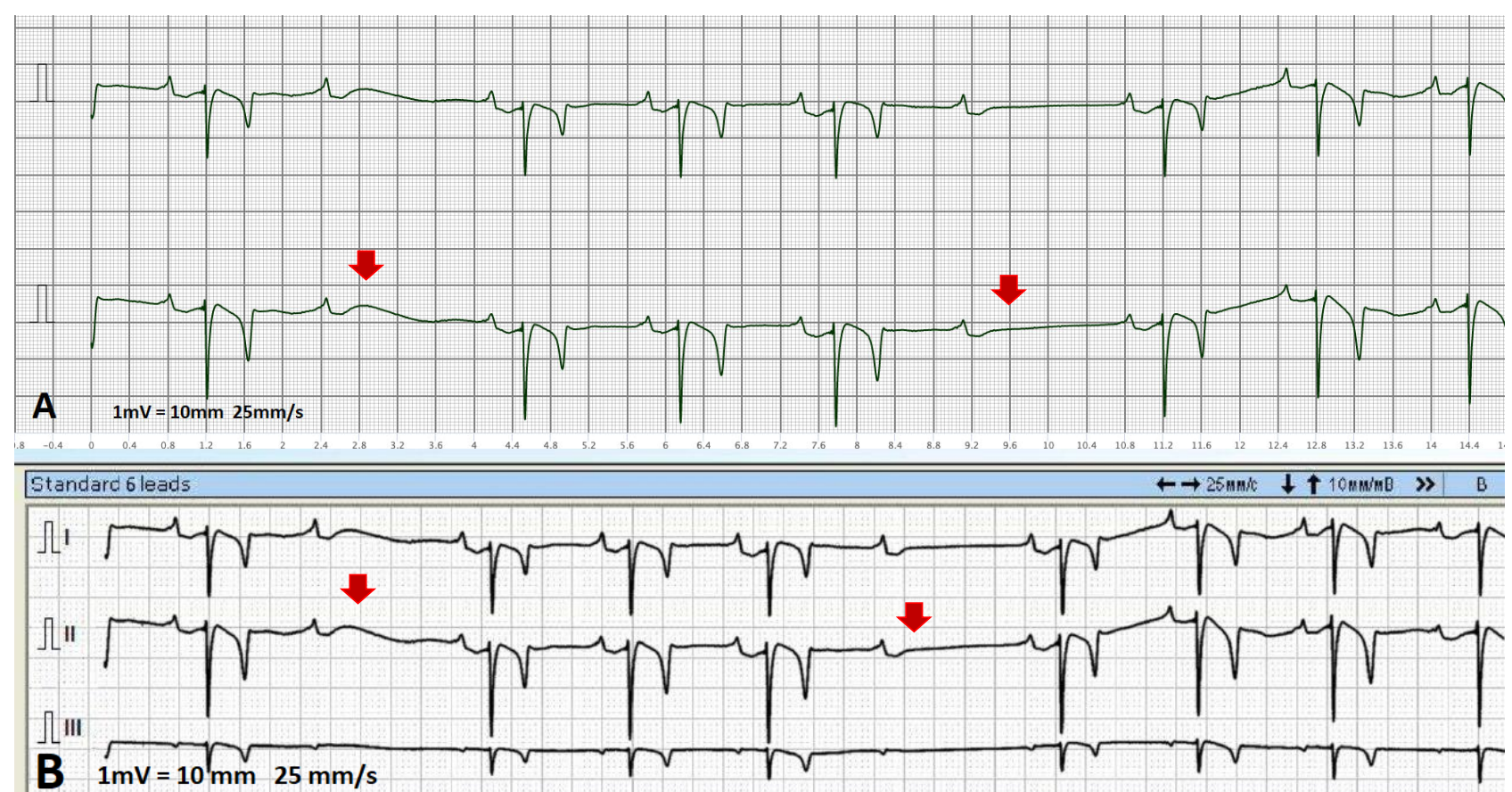

Fig. 4. Example of ECG with second degree AVB first Mobitz type recorded simultaneously with a portable ECG monitor (A) and standard electrocardiograph (B). It can be seen that in each cycle there are increasing PR intervals before the omission. Blocked QRST is signed with an arrow (Schwarzwald, 2015) 
Electrocardiographic intervals and amplitudes of the waves. Electrocardiographic intervals can be reliably $(\mathrm{P}<0.001)$ measured on ECG recordings from a portable ECG monitor. Heart rate showed an excellent correlation between the standard electrocardiograph and portable
ECG monitor, PR interval, QRS width, QT interval and P and $\mathrm{S}$ amplitudes had high correlation as well. The correlation coefficients for continuous electrocardiographic parameters are displayed in the Figure 5 and Table 3.

Table 3

Correlation coefficient of electrocardiographic continuous parameters

\begin{tabular}{ccccccc}
\hline & HR & PR interval & QRS interval & QT interval & P wave amplitude & S wave amplitude \\
\hline$r^{2}$ & 0,98 & 0,98 & 0,97 & 0,97 & 0,96 \\
\hline
\end{tabular}

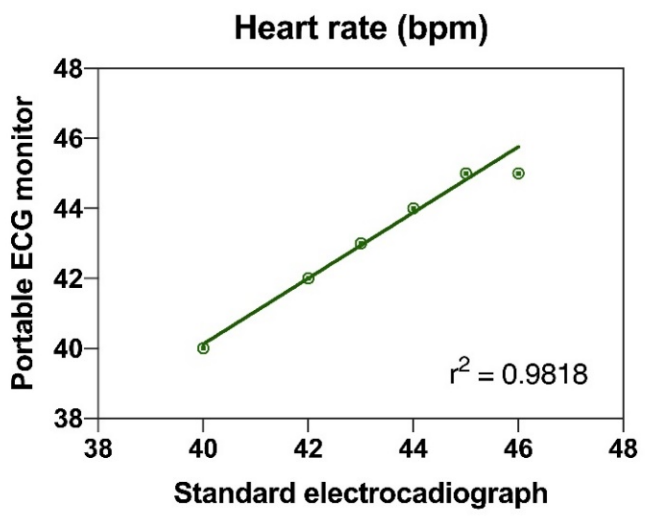

PR interval (ms)

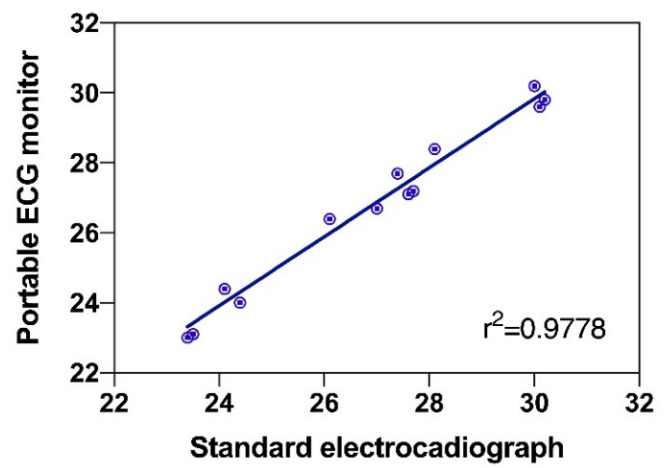

QT interval (ms)

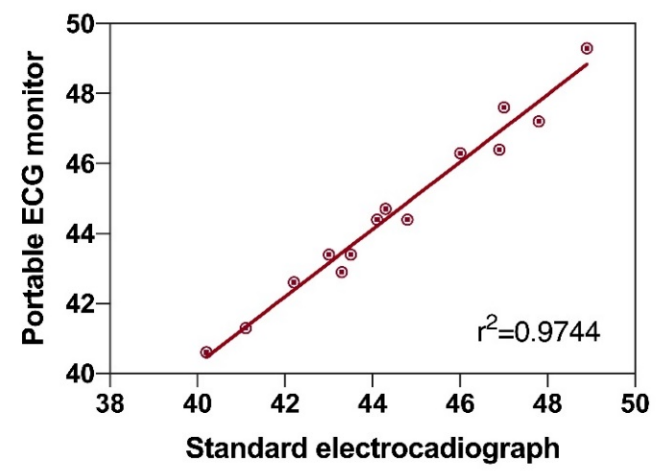

S wave amplitude $(\mathrm{mV})$

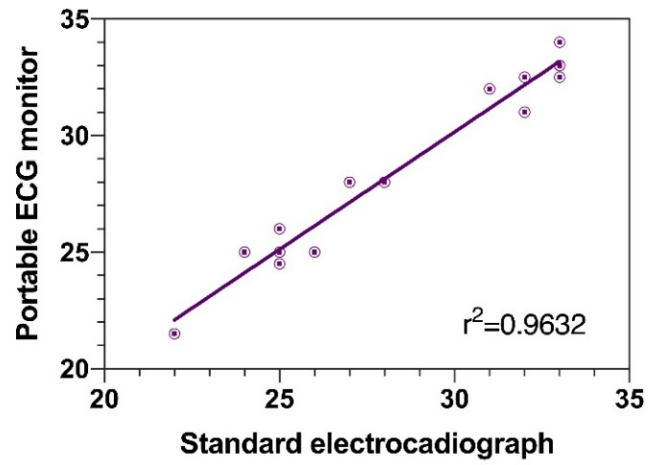

Fig. 5. Linear correlation of continuous ECG parameters $\left(r^{2}\right)$ between the portable ECG-monitor and the standard electrocardiograph in the study population. Heart rate correlated excellent between the two recording devices, and PR and QRS and QT duration, and amplitudes of $\mathrm{P}$ and $\mathrm{S}$ waves as well

\section{Discussion}

The study demonstrates that the portable ECG monitor can be used for diagnostics of cardiac arrhythmias in athletic horses. This system can be useful for the diagnosis of latent pathologies, which detection is only possible during physical activity.

Only 2 of the 196 entries recorded with a portable ECG monitor (1\%) had poor quality, indicating a high quality recording of potential changes in the heart from the animal's body surface during rest, as well as during exercise.
ECG recordings made with a portable ECG monitor allow to detect arrhythmias and other ECG changes with accuracy, compared to a standard electrocardiograph.

Most of the arrhythmias in horses have an asymptomatic course of development and progression and are only detectable during physical activity (Mitchell, 2019). An easy-to-use, portable ECG monitor allows screening for high-risk horses - athletes, post-operative animals etc. - to detect arrhythmias and begin treatment in time.

Portable ECG monitor is the first ukrainian electrocardiograph developed and designed specifically for ECG studies in animals with the possibility of longterm ambulatory ECG registration (10-12 hours in a row), 
with the ability to display the curve in real time during the movement of animals.

\section{Conclusions}

Horses with supraventricular tachycardia are predisposed for occurrence of atrial fibrillation and it is recommended to monitor such patients regularly. There are plenty of automated diagnostic systems with arrhythmia detection, but here is still no such system for horses. It is preconditioned by the appearance of equine ECG, specifically negative $\mathrm{S}$ waves in QRS complexes and various morphology and amplitude of $\mathrm{T}$ waves. This research is the basis for further collaborations with KPI researchers for the development of an automated diagnostic system.

\section{References}

Allen, K. J., Young, L. E., \& Franklin, S. H. (2015). Evaluation of heart rate and rhythm during exercise. Equine Vet Educ, 28(2), 99-112. doi: $10.1111 /$ eve. 12405 .
Mitchell, K. J. (2019). Equine Electrocardiography. Vet Clin North Am Equine Pract., 35(1), 65-83. doi: 10.1016/j.cveq.2018.12.007.

Reed, S. M., Bayly, W. M., \& Sellon, D. C. (2018) Equine Internal Medicine, Fourth edition. Elsevier, St. Louis, Missouri, 413-418. https://www.elsevier.com/ books/equine-internal-medicine/reed/978-0-32344329-6.

Schwarzwald, C. C. (2015). How to analyze exercising ecgs. In: Veterinary Cardiovascular Society, Burleigh Court, Loughborough, 13 November 2015 - 13 November 2015, 1-32. doi: 10.5167/uzh-119441.

Verheyen, T., Decloedt, D., De Clercq, D., Deprez, P., Sys, S. U., \& van Loon, G. (2010). Electrocardiography in horses - part 1: How to make a good recording. Vlaams Diergen Tijds, 79, 331-336. https://vdt.ugent.be/sites/default/files/art79501.pdf.

Young, L. (2004). Diseases of the heart and vessels. In: Hinchcliff K.W., Kaneps A.J., Geor R.J. (editors). Equine Sports Medicine and Surgery - Basic and Clinical Sciences of the Equine Athlete. Elsevier Limited, Edinburgh, 728-767. 